\title{
Overcoming obstacles to establish a multidisciplinary team approach to hepatobiliary diseases: a working model in a Caribbean setting
}

This article was published in the following Dove Press journal:

Journal of Multidisciplinary Healthcare

28 May 2014

Number of times this article has been viewed

\author{
Shamir O Cawich' \\ Peter B Johnson ${ }^{2}$ \\ Sundeep Shah ${ }^{2}$ \\ Patrick Roberts ${ }^{2}$ \\ Milton Arthurs ${ }^{2}$ \\ Trevor Murphy ${ }^{2}$ \\ Kimon O Bonadie ${ }^{2}$ \\ Ivor W Crandon' \\ Hyacinth E Harding' \\ Mohammed Abu Hilal ${ }^{3}$ \\ Neil W Pearce ${ }^{3}$ \\ 'Department of Clinical Surgical \\ Sciences, University of the West \\ Indies, St Augustine Campus, Trinidad \\ and Tobago; ${ }^{2}$ Faculty of Medical \\ Sciences, University of the West \\ Indies, Mona Campus, Kingston, \\ Jamaica; ${ }^{3}$ University Surgical Unit, \\ Southampton General Hospital, \\ Southampton, United Kingdom
}

Introduction: By providing a structured forum to exchange information and ideas, multidisciplinary team meetings improve working relationships, expedite investigations, promote evidence-based treatment, and ultimately improve clinical outcomes.

Methods: This discursive paper reports the introduction of a multidisciplinary team approach to manage hepatobiliary diseases in Jamaica, focusing on the challenges encountered and the methods used to overcome these obstacles.

Conclusion: Despite multiple challenges in resource-limited environments, a multidisciplinary team approach can be incorporated into clinical practice in developing nations. Policy makers should make it a priority to support clinical, operational, and governance aspects of the multidisciplinary teams.

Keywords: decision-making, cancer, health care policy

\section{Introduction}

Once policy makers recognized that there was clinical value in a multidisciplinary team (MDT) approach to disease management, it became the standard of care in most modern health care delivery systems. ${ }^{1-5}$ By providing a structured forum in which to exchange information and ideas, MDT meetings improve working relationships, expedite investigations, promote evidence-based treatment, and ultimately improve clinical outcomes. ${ }^{5-14}$

The MDT approach to disease management is not practiced routinely in the Anglophone Caribbean. ${ }^{15}$ This is because the region is composed of several small countries (with as few as 5,000 persons in Monserrat ${ }^{16}$ ) and it is commonplace for a small cadre of doctors to be responsible for health care for an entire nation. Frequently, subspecialty support is unavailable and community doctors are responsible for general patient care, often in remote and isolated areas. ${ }^{15}$ In this setting, medical decisions are made autonomously by attending doctors with very little collaborative input. Even in the more populous islands such as Jamaica (2.7 million) ${ }^{16}$ and Trinidad (1.3 million) ${ }^{17}$ where there is a larger cadre of doctors, the "sole practitioner culture" prevails and medical decisions are still made in an autocratic manner without routine application of MDT principles.

There has been change over the past few years as more medical graduates are exposed to practice in developed nations during subspecialty training. ${ }^{15}$ After this type of exposure, a group of clinicians interested in hepatobiliary disorders embraced the concept and formed the hepatobiliary MDT at a tertiary care training hospital in Jamaica in 2011. We report the challenges encountered while attempting to change
Correspondence: Shamir O Cawich Department of Clinical Surgical Sciences, University of the West Indies, St Augustine Campus, Trinidad and Tobago Tel +l 8687989627

+I 8683157414

Email socawich@hotmail.com 
the traditional structure of medical practice by establishing a functional MDT in this setting. This task was approached in six phases, which are described herein.

\section{Phase I: identifying common interest groups}

As the first step, a group of clinicians met to discuss the prospect of a MDT in the local health care setting. In this instance, the core group comprised young clinicians who were all within 5 years of subspecialty training in various disciplines: two hepatobiliary surgeons, two radiologists, two gastroenterologists, and one medical oncologist. These were clinicians who were exposed to the MDT concept in training hospitals outside of the Caribbean region.

These clinicians had returned to the region to commence their clinical practices and had all taken up attending grade posts at the University of the West Indies (Kingston, Jamaica). This is a regional medical training institution that was founded in 1948 to serve the 17 countries in the Anglophone Caribbean. ${ }^{18}$ It is affiliated with the University Hospital - a 500-bed hospital that serves as the sole tertiary referral center for hepatobiliary services in Jamaica and countries in the northern Caribbean. ${ }^{19}$

The common threads between the members of this core group were a shared interest in hepatobiliary diseases, a common institutional employer, and the unified desire to follow MDT principles in their practice. Bringing these individuals with common goals together facilitated the formation of the core MDT group. A mission statement was formulated: to improve the standard of care through multidisciplinary collaboration for clinical decision-making and interdisciplinary support.

\section{Phase 2: feasibility study}

In order to document local medical practice, a retrospective audit of tertiary care training hospitals across the Anglophone Caribbean was performed and it was revealed that an MDT approach to hepatobiliary diseases was not routinely practiced. ${ }^{15}$ Combined with international data documenting the benefits of the MDT process, ${ }^{1-14}$ these regional data were used to support the call for implementation of MDT principles to improve national health care standards.

However, the medical community was generally skeptical. ${ }^{15}$ Established clinicians believed that change was unnecessary because there was no problem in the way that hepatobiliary diseases were managed. Their reservations and reluctance to participate created a subtle divide between the established clinicians and those who supported the MDT process. The fact that most supporters were younger, more recent graduates with subspecialty training added an extra dimension of difficulty to the process.

\section{Phase 3: engage stakeholders}

The MDT group appreciated the potential for persons to erect barriers if they did not feel they were a part of the process. ${ }^{20}$ Success in this venture required stakeholder engagement to develop a team spirit with all stakeholders aiming for a unified goal. The action plan was approached in two tiers.

First, deliberate attempts were made to reach out to the established clinicians individually through personal communication and weekly invitations, reinforcing at every opportunity that their opinions were valued at the MDT forum. It was hoped this would give them a sense of belonging to the MDT group. The response, however, was poor.

Simultaneously, the core group approached the facility administration to lobby for institutional recognition, technical support, and dedicated staffing. There was no active opposition but no dedicated funding, equipment, space, or support staff were made available for this purpose.

It became evident that any success in this venture would be self-driven. Therefore, the core group looked internally and assigned members the responsibilities for MDT needs: governance, documentation, audiovisual services, and meeting coordination. The roles were regularly reassigned to evenly distribute responsibilities and it was understood that these tasks would be completed without remuneration.

\section{Phase 4: financial planning}

Due to budgetary limitations, funding for this venture was not available from either the hospital or the training facilities, which was unfortunate. However, this challenge was overcome using the following three approaches.

First, many of the hardware items used in MDT meetings, such as personal computers, software, and audiovisual equipment, were members' personal property.

Second, wherever possible, we made full use of free software. We utilized WhatsApp ${ }^{\circledR}$ (WhatsApp Inc., Mountain View, CA, USA) and Google Mail ${ }^{\circledR}$ (Google Inc., Mountain View, CA, USA) groups to coordinate MDT activities and disseminate information rapidly. Computed tomography images were viewed using Osiri $\mathrm{X}^{\circledR}$ Digital Imaging and Communications in Medicine (DICOM) imaging software (v 5.6; Pixmeo, Bernex, Switzerland), which is available freely on the internet. Electronic images were shared electronically using Dropbox ${ }^{\circledR}$ (Dropbox Inc., San Francisco, CA, USA), which is also available freely on the internet. 
Third, we actively forged public-private partnerships, seeking donations to procure hardware items such as video conferencing hardware, surgical disposables, and/or other specialized equipment that were needed. The partnerships were not limited to funding. Through interpersonal relationships, a link to the hepatobiliary team at the University Hospital Southampton, Southampton, UK was maintained to discuss complex cases by video conferencing (Medical Video Conferencing Ltd, Bude, UK). These overseas specialist teams provided their advice and assistance at no charge.

\section{Phase 5: implementation}

After overcoming these challenges, the first MDT meeting was held in September 2011 and was led by the core group of attending grade hepatobiliary surgeons, radiologists, gastroenterologists, and oncologists. Weekly MDT meetings were held to discuss the management of patients with a spectrum of hepatobiliary diseases. Each case discussion began with a detailed clinical summary from the clinicians followed by real-time review of medical imaging by radiologists and then a wholesome discussion between all team members. All management decisions were made after a consensus was reached during discussion at MDT meetings.

All information exchanged at the meetings was documented and the final decision taken by the MDT was recorded. Although it was not required by any institutional protocols, the core group agreed beforehand to abide by any decision or plans made collectively by the MDT group. Arriving at this agreement before implementation reduced the potential for interpersonal conflicts during meetings. After clinical decision-making and treatment planning were completed, the attending physicians were responsible for meeting the patients in a clinical setting to execute the MDT plan and deliver clinical care.

Initially, there was minimal engagement from established clinicians, particularly in relation to referrals and care planning. Despite this, the MDT group continued to hold their weekly meetings and core members agreed that all patients they encountered with hepatobiliary diseases, whether in public or private practice, would be discussed. In the first year, all cases discussed were "self-referrals" that originated from the core group. However, in the second year, established clinicians engaged in the MDT discussions and referred their patients.

\section{Phase 6: regular audit}

We prioritized documentation because we recognized that proper recordkeeping was necessary in order to demonstrate tangible benefits for the health care system. This facilitated regular practice audits.

During the first 3 months, the mean duration of the meetings was 40 minutes and accommodated a mean of 4.75 cases per session. There was a steady increase in workload over time, culminating in a mean meeting duration of 90 minutes for eight case discussions per meeting during months 18-20.

For all cases, we documented the attending doctors' clinical plans before meetings and the MDT plans after case discussions. When compared, there was a change in the treatment plan in $48 \%$ of cases after MDT discussion, suggesting that patient care was being influenced in some way by the process. We recognize that the value of the MDT ultimately lies in improved clinical outcomes, but a change in these outcomes will not be fully evident at this early interval. The long-term outcome measures such as resection rates, morbidity, and mortality are being accrued and should be examined at the 5-year interval.

Apart from the benefits demonstrable through audits, there were other tangible benefits to this exercise. The regular interactions between various disciplines gave MDT members a better understanding of the challenges in a system with limited resource ${ }^{21}$ and allowed patients to be steered effectively through the health care system. As a result, our patients could be streamlined along expedited therapeutic pathways.

The process empowered MDT members, instilling a feeling of satisfaction with their working environment. ${ }^{22}$ All members reported a subjective improvement in interpersonal working relationships, personal satisfaction at the workplace, and a sense of belonging/team spirit. ${ }^{22}$

The formation of an MDT has encouraged the centralization of hepatobiliary services..$^{19}$ The volume of cases encountered by the MDT has increased, yielding larger series of hepatobiliary diseases. The MDT now actively maintains several registries populated with pooled regional data that can be used in the future to construct guidelines geared for Caribbean practice.

\section{Conclusion}

Despite multiple challenges in an underfunded and resourcelimited environment, MDTs can be incorporated into clinical practice. Policy makers should make it a priority to support clinical, operational, and governance aspects of the MDTs. The next step forward should be to develop an inclusive MDT environment that encompasses the entire region.

\section{Disclosure}

The authors report no conflicts of interest in this work. 


\section{References}

1. Patkar V, Acosta D, Davidson T, Jones A, Fox J, Keshtgar M. Cancer multidisciplinary team meetings: evidence, challenges, and the role of clinical decision support technology. Int J Breast Cancer. 2011;2011:831605.

2. Calman K, Hine D. A Policy Framework for Commissioning Cancer Services: A Report by the Expert Advisory Group on Cancer to the Chief Medical Officers of England and Wales. Department of Health, The Welsh Office; 1995. Available from: http://www.dhcarenetworks. org.uk/_library/Resources/ICN/Policy_documents/Calman_Hine.pdf. Accessed January 5, 2014.

3. van Leeuwen AF, Voogt E, Visser A, van der Rijt CC, van der Heide A. Considerations of healthcare professionals in medical decision-making about treatment for clinical end-stage cancer patients. J Pain Symptom Manage. 2004;28(4):351-355.

4. van Nes JG, van de Velde CJ. [The multidisciplinary breast cancer care team: promoting better care]. Ned Tijdschr Geneeskd. 2005;149(35): 1929-1931. Dutch.

5. Fennell ML, Das IP, Clauser S, Petrelli N, Salner A. The organization of multidisciplinary care teams: modeling internal and external influences on cancer care quality. J Natl Cancer Inst Monogr. 2010;40: 72-80.

6. Back MF, Ang EL Ng WH, et al. Improvements in quality of care resulting from a formal multidisciplinary tumour clinic in the management of high-grade glioma. Ann Acad Med Singapore. 2007;36(5):347-351.

7. Stephens MR, Lewis WG, Brewster AE, et al. Multidisciplinary team management is associated with improved outcomes after surgery for esophageal cancer. Dis Esophagus. 2006;19(3):164-171.

8. Forrest LM, McMillan DC, McArdle CS, Dunlop DJ. An evaluation of the impact of a multidisciplinary team, in a single centre, on treatment and survival in patients with inoperable non-small-cell lung cancer. Br J Cancer. 2005;93(9):977-978.

9. Junor EJ, Hole DJ, Gillis CR. Management of ovarian cancer: referral to a multidisciplinary team matters. Br J Cancer. 1994;70(2): $363-370$.

10. Dillman RO, Chico SD. Cancer patient survival improvement is correlated with the opening of a community cancer center: comparisons with intramural and extramural benchmarks. J Oncol Pract. 2005;1(3): 84-92.
11. Davison AG, Eraut CD, Haque AS, et al. Telemedicine for multidisciplinary lung cancer meetings. J Telemed Telecare. 2004;10(3): 140-143.

12. Bouvier AM, Bauvin E, Danzon A, et al. Place of multidisciplinary consulting meetings and clinical trials in the management of colorectal cancer in France in 2000. Gastroenterol Clin Biol. 2007;31(3): 286-291.

13. Davies AR, Deans DA, Penman I, et al. The multidisciplinary team meeting improves staging accuracy and treatment selection for gastroesophageal cancer. Dis Esophagus. 2006;19(6):496-503.

14. Burton S, Brown G, Daniels IR, Norman AR, Mason B, Cunningham D; Royal Marsden Hospital, Colorectal Cancer Network. MRI directed multidisciplinary team preoperative treatment strategy: the way to eliminate positive circumferential margins? Br J Cancer. 2006;94(3): 351-357.

15. Cawich SO, Pearce NW, Abu-Hilal MX. Surgical sub-specialty training in HPB surgery for the Caribbean. West Indian Med J. 2012; 61(Suppl 4):58.

16. Crandon IW, Harding HE, Cawich SO, Webster D. Complicated head trauma from machete wounds: the experience from a tertiary referral hospital in Jamaica. Int J Inj Contr Saf Promot. 2011;28(4):1-5.

17. Islam S, Harnarayan $\mathrm{P}$, Cawich SO, et al. Epidemiology of diabetic foot infections in an eastern Caribbean population: a prospective study. Perm J. 2013;17(2):37-40.

18. Crandon IW, Harding HE, Cawich SO, Williams EW, Williams-Johnson J. Emergency department physician training in Jamaica: a national public hospital survey. BMC Emerg Med. 2008;8:11.

19. Johnson PB, Cawich SO, Roberts P, et al. Variants of hepatic arterial supply in a Caribbean population: a CT based study. Clin Radiol. 2013;68:823-827.

20. Cawich SO, Harding HE, Crandon IW, et al. Leadership in surgery for public sector hospitals in Jamaica: strategies in the operating room. Perm J. 2013;17(3):e121-e125.

21. Cawich SO, Tennant IA, McGaw CD, Harding HE, Walters CA, Crandon IW. Infection control practice in the operating room: staff adherence to existing policies in a developing country. Perm J. 2013;17(3):e114-e118.

22. Cawich SO, Abu-Hilal M, Simpson LK, Pearce NW. Training for hepatobiliary surgery in the modern laparoscopic era. West Indian Med J. 2013;62(Suppl 4):24-25.
Journal of Multidisciplinary Healthcare

\section{Publish your work in this journal}

The Journal of Multidisciplinary Healthcare is an international, peerreviewed open-access journal that aims to represent and publish research in healthcare areas delivered by practitioners of different disciplines. This includes studies and reviews conducted by multidisciplinary teams as well as research which evaluates the results or conduct of such teams or

\section{Dovepress}

healthcare processes in general. The journal covers a wide range of areas and welcomes submission from practitioners at all levels, from all over the world. The manuscript management system is completely online and includes a very quick and fair peer-review system. Visit http://www.dovepress.com/testimonials.php to read real quotes from published authors. 